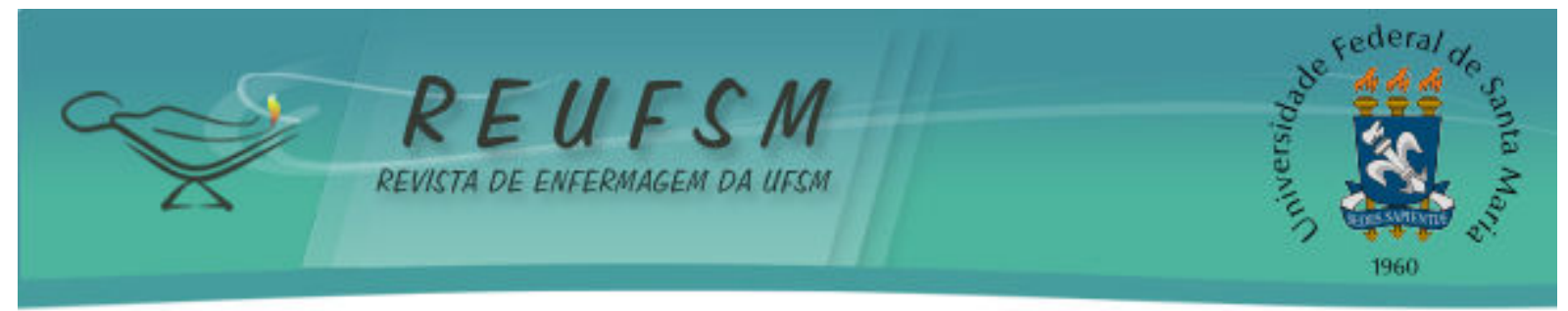

ARTIGO ORIGINAL

\title{
TRABALHO DE ENFERMAGEM NO CENTRO DE ATENÇÃO PSICOSSOCIAL: ESTRESSE E ESTRATÉGIAS DE COPING
}

\section{NURSING WORK IN PSYCHOSOCIAL CARE CENTER: STRESS AND COPING STRATEGIES \\ TRABAJO DE ENFERMERÍA EN CENTRO DE ATENCIÓN PSICOSOCIAL: EL ESTRÉS Y LAS ESTRATEGIAS DE AFRONTAMIENTO}

\author{
Daniele Cabral Avelino ${ }^{1}$ \\ Priscilla Maria de Castro Silva ${ }^{2}$ \\ Lorena de Farias Pimentel Costa ${ }^{3}$ \\ Elisângela Braga de Azevedo ${ }^{4}$ \\ Alynne Mendonça Saraiva ${ }^{5}$ \\ Maria de Oliveira Ferreira Filha ${ }^{6}$
}

Doi: $10.5902 / 2179769214163$

RESUMO: Objetivos: identificar os sentimentos vivenciados no trabalho em saúde mental; conhecer estratégias de coping referidas pelos profissionais de enfermagem. Método: trata-se de um estudo exploratório-descritivo de abordagem qualitativa realizado através de entrevista semiestruturada com 12 profissionais de enfermagem do CAPS III, em Campina Grande-PB. A análise ocorreu com base na técnica de conteúdo de Bardin, que resultou na criação de duas categorias: Sentimentos e estresse no trabalho em saúde mental; Estratégias de coping. Resultados: sentimentos como insegurança, frustação e esgotamento emocional atuaram como desencadeadores do estresse dos profissionais que trabalham no CAPS. Para tanto, foram citadas algumas estratégias, como possibilidades de atenuar o estresse, como: o apoio social, a música e espaços de escuta. Conclusões: verificou-se a necessidade de apoio psicológico aos profissionais de enfermagem, por enfrentarem fatores estressores em seu cotidiano, exigindo um planejamento estratégico melhor direcionado por parte dos gestores e equipe interdisciplinar que atuam nesses serviços.

Descritores: Esgotamento profissional; Equipe de enfermagem; Serviços de saúde mental.

ABSTRACT: Objectives: to identify the feelings experienced at work in mental health; learn coping strategies reported by nursing professionals. Method: this is an exploratorydescriptive qualitative study conducted by semi-structured interviews with 12 nursing professionals of CAPS III, in Campina Grande-PB. The analysis was based on Bardin content technique, which resulted in the creation of two categories: Feelings and stress on mental health work; Coping strategies. Results: feelings of insecurity, frustration and emotional

\footnotetext{
${ }^{1}$ Enfermeira. Graduada pela Faculdade de Ciências Médicas de Campina Grande. Campina Grande - PB/Brasil. dane.cabral@hotmail.com

2 Enfermeira. Doutoranda pelo Programa de Pós-Graduação em Enfermagem da Universidade Federal da Paraíba - PPGEnf/UFPB. Docente do curso Enfermagem da Universidade Federal de Campina Grande. João Pessoa PB/Brasil. priscillamcs@hotmail.com

${ }^{3}$ Enfermeira. Mestranda pelo Programa de Pós-Graduação em Enfermagem da Universidade Federal da Paraíba - PPGEnf/UFPB. João Pessoa - PB/Brasil. lorenafarias@outlook.com

${ }^{4}$ Enfermeira. Doutora pelo Programa de Pós-Graduação em Enfermagem da Universidade Federal da Paraíba PPGEnf/UFPB. João Pessoa - PB/Brasil. elisaaz@terra.com.br

${ }^{5}$ Enfermeira. Doutoranda pelo Programa de Pós-Graduação em Enfermagem da Universidade Federal da Paraíba PPGEnf/UFPB. Docente do curso Enfermagem da Universidade Federal de Campina Grande. João Pessoa PB/Brasil. alynnems@hotmail.com

${ }^{6}$ Enfermeira. Doutora pelo Programa de Pós-Graduação em Enfermagem da Universidade Federal do Ceará. Professor Adjunto IV do curso de Enfermagem da Universidade Federal da Paraíba. João Pessoa - PB/Brasil. marfilha@yahoo.com.br
} 


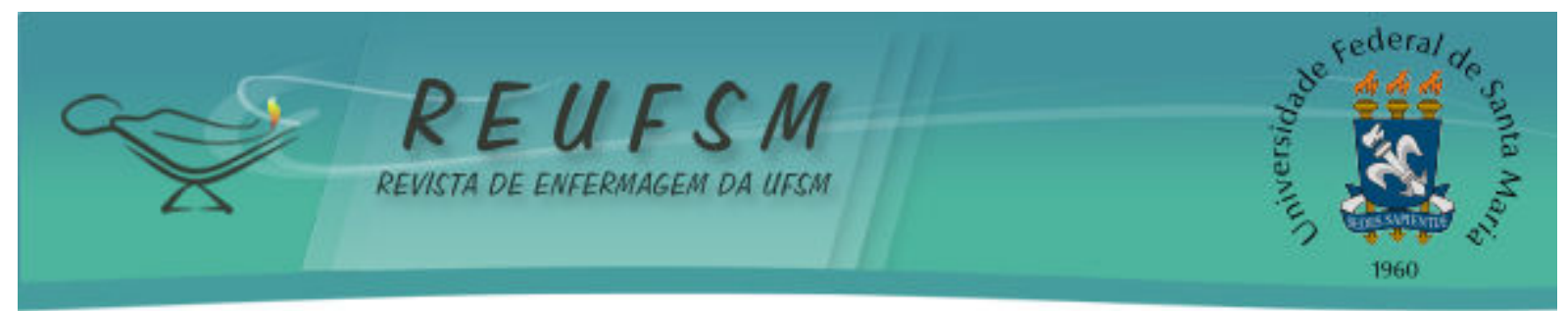

exhaustion acted as triggers of stress of professionals working at CAPS. Therefore, some strategies were mentioned as possibilities of alleviating stress, such as social support, music and listening spaces. Conclusions: there was the need for psychological support to nursing professionals, for facing stress factors in their daily lives, demanding a betterconducted strategic planning by managers and the interdisciplinary team working in these services.

Descriptors: Burnout, professional; Nursing staff; Mental health services.

RESUMEN: Objetivos: identificar los sentimientos experimentados en trabajo en salud mental; conocer estrategias de afrontamiento citadas por los profesionales de enfermería. Método: estudio cualitativo exploratorio-descriptivo, entrevistas semi-estructuradas con 12 enfermeros CAPSIII, en Campina Grande (PB, Brasil). El análisis se basó en la técnica de contenido de Bardin, creando dos categorías: sentimientos y el estrés laboral en el trabajo en salud mental; estrategias de afrontamiento. Resultados: sentimientos como inseguridad, frustración y agotamiento emocional actuaron como desencadenantes del estrés de los profesionales que trabajan en el CAPS. Por ello, algunas estrategias fueron mencionados como posibilidades de aliviar el estrés, como el apoyo social, la música y espacios de escucha. Conclusiones: se verificó la necesidad de apoyo psicológico a los profesionales de enfermería, que enfrentan factores de estrés en su vida cotidiana, exigiendo una mejor planificación estratégica dirigida por gerentes y el equipo interdisciplinar que trabaja en ellos.

Descriptores: Agotamiento profesional; El personal de enfermeria; Servicios de salud mental.

\section{INTRODUÇÃO}

Após o advento da Reforma Psiquiátrica e as discussões produzidas pelo Movimento dos Trabalhadores em Saúde Mental, as práticas de cuidado no campo da saúde mental vêm sendo transformadas e repensadas de forma ampliada, integrando ações sociais de cunho cultural, econômico, político e legal.

Os movimentos sociais em prol da mudança na assistência em saúde mental culminaram na aprovação da Lei n.10.216 de 6 de abril de 2001, que redirecionou a assistência em saúde mental no Brasil, oferecendo tratamento em serviços de base comunitária e dispondo sobre a proteção e os direitos das pessoas em sofrimento psíquico. No modelo de atenção em saúde mental atualmente proposto, preconiza-se a diminuição da oferta de leitos hospitalares e a criação de serviços que substituam os antigos manicômios. ${ }^{1}$

Dentre os serviços substitutivos que compõe a rede de saúde mental, destacam-se os Centros de Atenção Psicossocial (CAPS), que propõem a gradativa substituição do sistema hospitalocêntrico de cuidados, conforme estabelece a legislação vigente. Tais modelos começaram a ser implantados de forma pontual, sendo disseminados gradativamente pelo território brasileiro. ${ }^{2}$

O município de Campina Grande no estado da Paraíba passou a apoiar a desinstitucionalização desde o ano 2004, subsidiado pelas três esferas de governo, redirecionando atenção para os usuários dos hospitais psiquiátricos locais.

Para fortalecer esse novo paradigma de atenção psicossocial, além da construção de novos espaços terapêuticos, foi preciso elencar profissionais que pudessem se envolver e participar de maneira efetiva na produção de cuidados em saúde mental, delineando um novo enfoque para o processo saúde/doença, centrado na pessoa e rompendo com o elo 


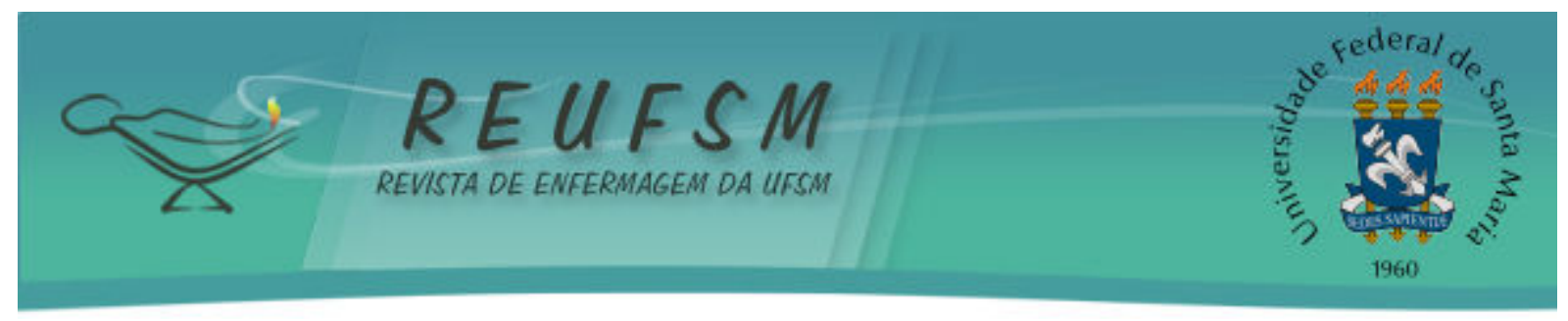

saber/poder, para poder promover uma cultura de autonomia dos sujeitos e estabelecer uma relação terapêutica de responsabilização.

0 trabalho em equipe nos moldes do novo modelo de atenção em saúde mental envolve múltiplas demandas, principalmente de cunho emocional. 0 convívio cotidiano com processos psíquicos elevados gera importante sobrecarga emocional. 0 constante envolvimento afetivo dos profissionais com os usuários do serviço e com outros profissionais que nem sempre compartilham dos mesmos ideais em relação à atenção, divergindo também no que diz respeito às intervenções terapêuticas sobre o sofrimento psíquico, contribuem para gerar sofrimento também nos profissionais de saúde mental, interferindo diretamente na qualidade do trabalho e na prestação de cuidados.

Além da rede de serviços substitutivos em saúde mental bem estruturada, fazemse necessários profissionais dotados de competências e habilidades para prestar cuidados aos portadores de sofrimento psíquico, baseados nos paradigmas da ressocialização e inclusão social. Entretanto, pressupõe-se que trabalhar em serviços de saúde, especialmente nos que são destinados à assistência em saúde mental, pode acarretar prejuízos aos profissionais desta área, que por sua vez podem ter implicações nas condições de trabalho, na assistência prestada e da vida social desses indivíduos. Conforme alguns autores ${ }^{3}$, o contato direto e contínuo com os usuários do serviço e outros profissionais pode resultar em ansiedade e frustração, além das exposições a cargas de trabalho físicas, fisiológicas, mecânicas.

A saúde mental dos indivíduos está permanentemente ligada à exposição e adaptação aos eventos estressores do cotidiano e, as respostas fisiológicas e psicológicas a estes eventos estão, de certo modo, relacionadas à capacidade de enfrentamento individual, interferindo favoravelmente ou não no equilíbrio dinâmico da pessoa envolvida. ${ }^{4}$

Acreditando que a apreensão de aspectos subjetivos dos profissionais que trabalham com portadores se sofrimento psíquico, favorecerá a tomada de decisões para melhoria na qualidade da saúde e na melhoria dos cuidados prestados, emergiram as seguintes questões norteadoras desse estudo: Quais os sentimentos vivenciados pelos profissionais de enfermagem no trabalho em saúde mental? Quais as estratégias de coping referidas por esses profissionais para lidar com as situações encontradas no cotidiano laboral? Sendo assim, esta pesquisa teve como objetivos: identificar os sentimentos vivenciados no trabalho em saúde mental; conhecer as estratégias de coping referidas pelos profissionais de enfermagem para lidar com as situações no cotidiano laboral.

\section{MÉTODO}

No sentido de viabilizar o desenvolvimento desta pesquisa, optou-se pela abordagem qualitativa e a tipologia exploratória, visto que favorecem a apreensão das experiências subjetivas que permeiam determinados acontecimentos. ${ }^{5}$

O cenário de investigação, no qual o pesquisador esteve inserido no mês de janeiro de 2010, foi um Centro de Atenção Psicossocial (CAPS III) em um município da Paraíba. A composição da amostra foi aleatória, não probabilística composta por acessibilidade, constituída por 12 profissionais da equipe de enfermagem que trabalham no CAPS III, entre técnicos e enfermeiros.

Foram elencados os seguintes critérios para inclusão dos sujeitos na pesquisa: fazer parte integrante da equipe de enfermagem. Todos os participantes foram esclarecidos sobre a proposta do estudo e convidados a leitura e assinatura do Termo de Consentimento Livre e Esclarecido (TCLE). Para coleta de material, utilizou-se um roteiro de entrevista semiestruturado, contendo questões relativas às condições de trabalho e a produção de cuidado vivenciada por estes profissionais. Os entrevistados foram 


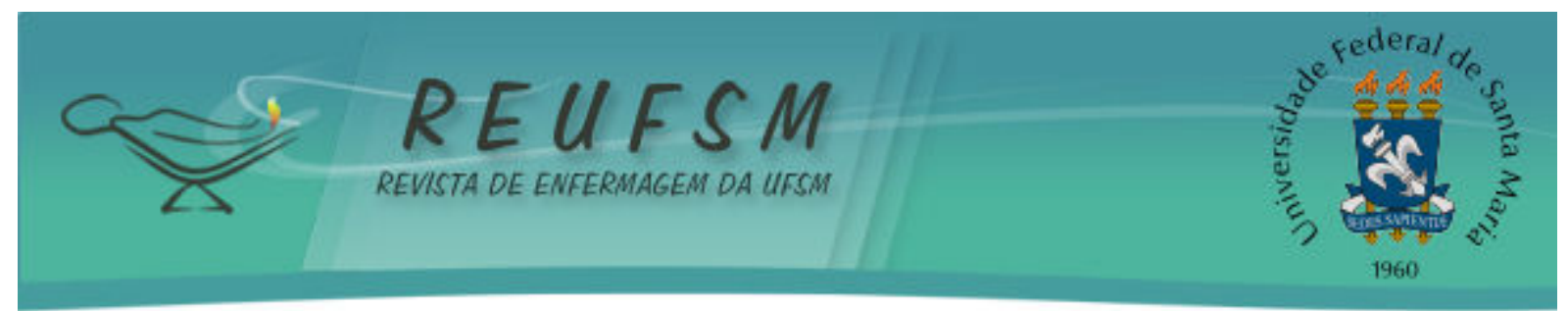

identificados conforme a ordem de realização da pesquisa, de E1 até E12. Os relatos foram gravados e discutidos à luz da análise de conteúdo do tipo categorial temática proposta por Bardin. ${ }^{6}$ Dessa forma, realizou-se a pré-exploração, a seleção de unidades de análise e, por fim, o processo de categorização e subcategorização.

Cumpriram-se rigorosamente, os preceitos éticos elencados na Resolução ${ }^{7}$ Conselho Nacional de Saúde (CNS), tendo a aprovação do Comitê de Ética em Pesquisa do Centro de Ensino Superior e Desenvolvimento (CEP/CESED), sob número: 0115.0.000.405-10.

\section{RESULTADOS E DISCUSSÃO}

Inicialmente, os profissionais foram questionados com a seguinte pergunta: "Como é para você trabalhar na área de saúde mental?” De acordo com as respostas concedidas, foi elaborada a seguinte categoria:

\section{Sentimentos e estresse no trabalho em saúde mental}

O trabalho ocupa importante papel na vida do ser humano por possibilitar sua inserção social e oferecer a manutenção da expectativa de vida planejada durante toda sua trajetória ${ }^{8}$, e isso só é possível mediante a satisfação pessoal que proporciona maior desempenho da atividade profissional a que cada um se propõe.

0 depoimento aponta que trabalhar em saúde mental, pode gerar sentimento de insegurança, seja pela pouca importância oferecida na formação profissional no que concerne a esta área de atuação, ou pelo próprio preconceito ainda existente com relação aos usuários. Observa-se também que o fator positivo demonstrado refere-se apenas à remuneração do serviço, que muitas vezes se sobrepõe as outras áreas, em virtude da dificuldade de se encontrar profissionais com habilidades necessárias para atuar nesses espaços.

Trabalhar com saúde mental tem um lado satisfatório e tem um lado frustrante também, pela questão financeira é bom, e é estressante por conta da insegurança que nós sentimos. (E. 05)

É importante ressaltar, porém, que a qualidade de vida do profissional que atua em saúde mental também pode apontar fragilidades que vão além da insegurança no desenvolvimento das ações de cuidado, como também à exposição a um ambiente envolvido por situações estressantes, principalmente diante das atitudes instintivas e abruptas por parte dos usuários, que consideradas diariamente podem ser somatizadas pelo cuidador e desencadeadoras de possíveis transtornos emocionais, na ótica da psicossomática. ${ }^{9}$

0 relato em destaque esclarece fielmente o sentimento intrínseco de sobrecarga, estresse emocional e a queixa clara de omissão do serviço quanto às situações estressoras vivenciadas pelos profissionais participantes deste estudo, que reconhecem a sua condição susceptível ao processo de adoecimento por estresse no ambiente de trabalho.

Eu acho muito estressante porque a sobrecarga é muito grande para o profissional e a gente não tem uma escuta que deveríamos ter. (E. 08)

É muito desgastante, porque o dia a dia nos deixa bastante estressados e acabamos descontando nas pessoas de casa.(E. 1) 


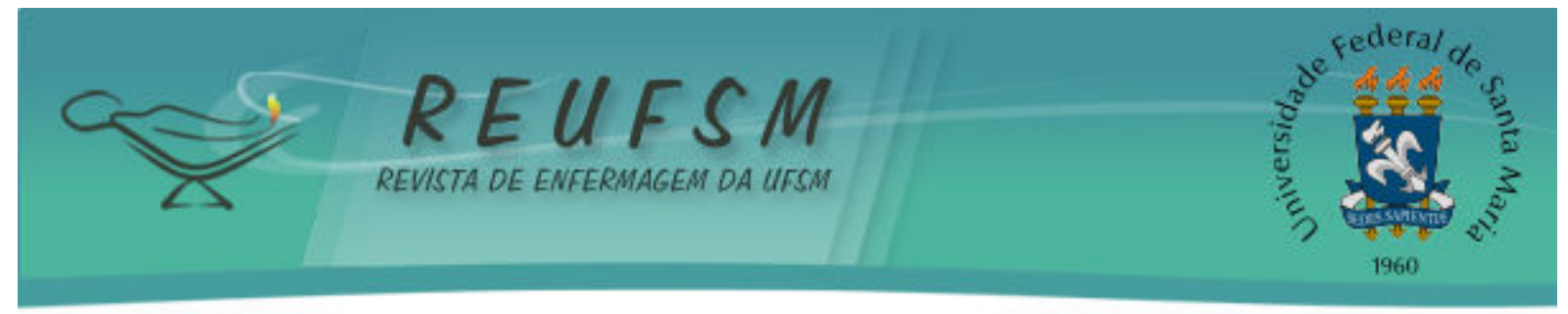

Condições de trabalho estressantes culminam em causar maiores impactos à saúde do indivíduo, neste caso, devido a sua capacidade cumulativa, com o passar do tempo e que quando se busca resistir continuamente a este sofrimento prolongado, uma doença ligada ao estresse pode ocorrer.

É importante observar no relato, que o estresse laboral tem influência sobre a família, muitas vezes podendo gerar um ciclo vicioso, onde o ambiente e as relações familiares acabam se tornando espaços produtores de estresse. Alguns autores já observaram uma relação negativa entre problemas laborais e família, o que significa que quanto mais os acontecimentos do trabalho interferem na família, menor a percepção de saúde no trabalho e quanto mais os acontecimentos na família interferem na realização do trabalho, menor a percepção de segurança e competência profissional. ${ }^{10}$

Portanto, percebe-se que a equipe multiprofissional e os gestores de saúde que atuam no serviço de atenção psicossocial, ainda permanecem dispersos quanto à percepção de alarmes sutis apresentados pelos profissionais de enfermagem. Tais alarmes revelam uma condição que pode ser desencadeadora de algum transtorno mental e, quando não há reconhecimento prévio destes alarmes e uma intervenção precisa baseada em um planejamento estratégico preventivo voltado para o profissional de saúde que, ao desempenhar sua função não está excluído enquanto ser humano de ser afetado por algum transtorno, as consequências serão percebidas ao longo do tempo.

Ser cuidador de paciente em situação de sofrimento psíquico demanda tempo, atenção e dedicação, entendidas como sobrecarga de trabalho, associada a incapacidade humana de compreender a patologia, acrescidas de expectativas frustradas a respeito da cura e estabilização do quadro. ${ }^{11}$

As frustrações e problemas cotidianos e laborais podem causar estresse, resultado em impactos negativos na saúde dos indivíduos. Aos gestores cabe desenvolver espaços de escuta, estratégias de cuidar dos cuidadores, a fim de minimizar os impactos causados pelo estresse em profissionais que atuam na saúde mental, dentre estes, os enfermeiros. ${ }^{12}$

Estar inserido no serviço de assistência em saúde mental enquanto profissional expõe o indivíduo a experiências que promovem uma invasão gradativa de sentimentos. Este fato exige uma relutância emocional intensa para que seja possível o desempenho da atividade junto ao usuário. Tal situação é claramente visualizada nos discursos que tratam de fatores estressores provenientes do desempenho diário, o que tem levado o profissional de enfermagem a utilizar mecanismos que possam minimizar maiores danos físicos e emocionais futuros.

Nesse sentido, foi questionado aos profissionais: “Quais as estratégias de enfrentamento utilizadas diante das dificuldades vivenciadas no cotidiano laboral?" A partir das respostas, emergiu-se a seguinte categoria:

\section{Estratégias de coping}

Foi observado que as estratégias de coping citadas foram: apoio social, representado pelo lazer com amigos, a música e espaços de escuta.

\section{Apoio social}

De acordo com alguns pesquisadores ${ }^{13}$, o apoio social possibilita que o indivíduo possa lidar com os eventos e condições estressoras funcionando como agente protetor da saúde. Dessa maneira, o apoio social funciona como mediador do estresse, à medida que, a pessoa se sente aceita, acolhida e cuidada pelas pessoas que estão ao seu redor e possui 


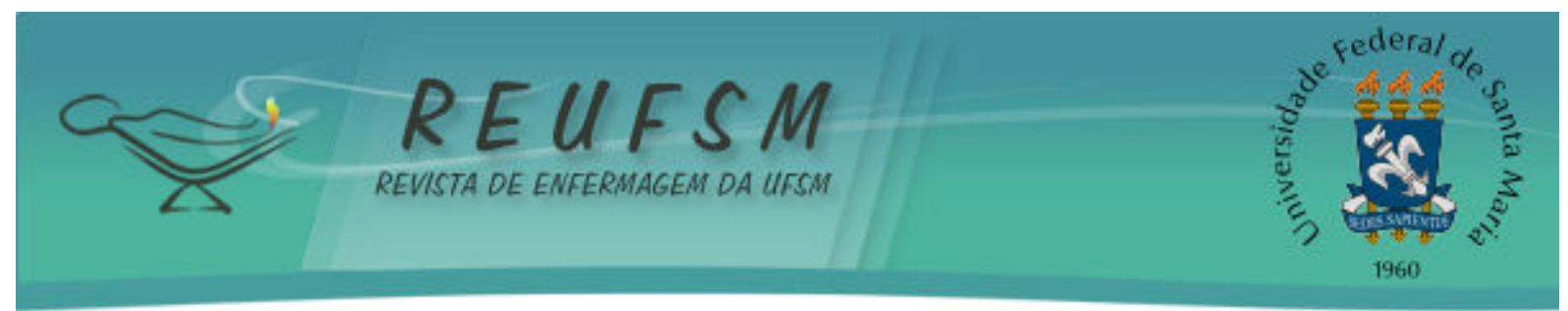

um grau de significação para ele, o nível de estresse pode ser controlado ou reduzido, como demonstram os depoimentos a seguir:

Adoro sair, sair com os amigos, barzinhos... São momentos que são necessários para que se quebre um clima mais de estresse do trabalho. (E. 09)

Gosto muito de sair como os amigos para tomar uma e esquecer $o$ estresse. (E. 03)

Dentro deste contexto, pode-se perceber que o álcool também vem sendo introduzido na vida cotidiana dos trabalhadores em saúde mental sutilmente, bem como retrata o último discurso citado acima, apresentando o etilismo como fator associado ao lazer, sendo utilizado de forma rotineira, pelo menos uma vez por semana, após o término dos plantões que antecedem o dia de folga nas saídas em grupo.

Nesse contexto, a rede de apoio social pode exercer influências nas condutas dos indivíduos, seja de forma positiva ou negativa, podendo promover a saúde do indivíduo ou funcionar como fonte promissora para comportamentos nocivos a ele, como é o caso do estímulo ao uso de álcool ou outras drogas.

\section{Música como refúgio}

A música já vem sendo utilizada nos serviços de saúde como instrumento terapêutico complementar, capaz de promover um ambiente mais tranquilo e acolhedor e estreitar os laços de segurança e confidencialidade que sustenta o eixo família - usuário profissional, além de propiciar um momento de relaxamento, de entrega, de escuta.

A utilização desta prática tem gerado resultados positivos por não ser realizada isoladamente, mas inserida no planejamento junto a outras medidas terapêuticas, tornando perceptível a contribuição desse recurso não apenas para usuários do serviço, mas também para a saúde mental dos profissionais, o que pode ser evidenciado no discurso abaixo.

Eu gosto muito da música, é algo que amo de paixão, e é através dela que eu tento não absorver o que eu vivi aqui. (E. 07)

Adoro música é algo que tira um pouco do meu estresse. (E. 03)

A música está presente no cotidiano de várias pessoas, utilizada como técnica de relaxamento, redutora do estresse e promotora de bem-estar. Inclui-se como benefício do uso da música a adequação do comportamento fisiológico do indivíduo, redução da dor e tensões corporais. ${ }^{14}$

Em uma pesquisa realizada sobre adoecimento dos trabalhadores de enfermagem, descobriu-se que a música é utilizada como uma técnica cognitiva que produz efeitos positivos no combate ao estresse laboral. ${ }^{15}$ Sendo assim, a música se faz importante no combate ao eventos estressores, configurando-se como um recurso simples, barato e que pode ser utilizando dentro e fora do ambiente de trabalho.

\section{Espaços de escuta}

Embora os novos dispositivos de saúde mental, propiciem benefícios assegurados pela legislação brasileira, seus principais focos ainda se constituem dos usuários e 


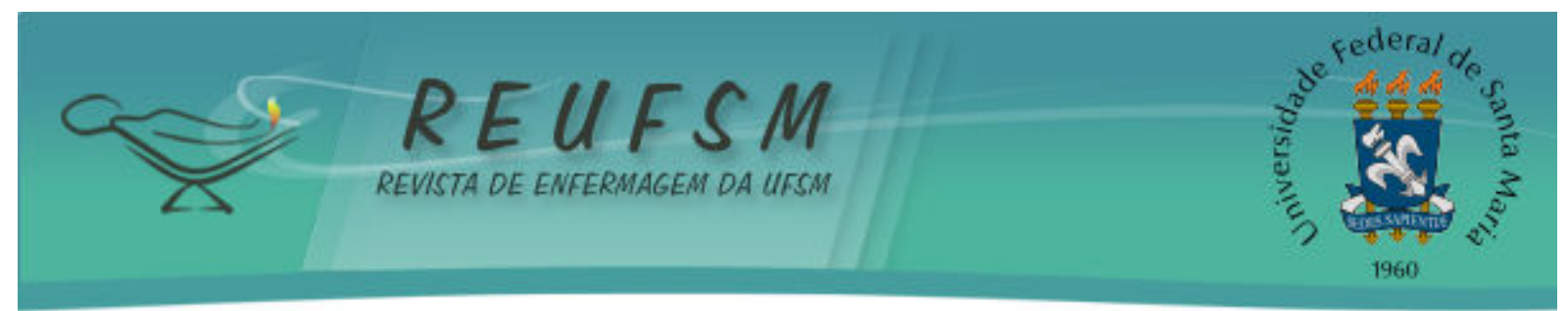

familiares, deixando muitas vezes, os profissionais dessa área em segundo plano. Portanto, ainda não é perceptível a garantia assistencial no cenário ocupacional para os trabalhadores inseridos nos serviços de atenção psicossocial. A ausência de espaços de cuidados a esses profissionais é descrita nas seguintes falas:

Seria bom, a escuta dos profissionais, para que eles possam falar de suas frustrações, eles possam de certa forma expressar seus sentimentos em relação ao que acontece dentro da instituição. (E. 06)

Gostaria que houvesse uma terapia voltada ao atendimento $e$ escuta dos profissionais. (E. 08)

0 exercício da enfermagem em atendimento a pessoa em sofrimento psíquico expõe o profissional a diversos momentos de estresse, em que a organização do trabalho e o cuidado ao usuário refletem diretamente na sua ocorrência. ${ }^{16}$

Diante disso, salienta-se a importância de preservar a saúde do trabalhador, no tocante as dimensões e a subjetividade individual, buscando o amenizar desgastes e compreendendo os conflitos favorecendo o bem-estar físico, o contexto social e o aspecto emocional. ${ }^{17}$

Vale ressaltar o quanto os profissionais em saúde mental podem apresentar alarmes psíquicos quando estão sob fatores estressores e que a ausência de reconhecimento acerca da ação desempenada e apoio emocional por meio institucional podem levar a acentuação desse risco, culminado em muitas situações ao acometimento pela síndrome de Burnout, exigindo do profissional atenção integral as formas de prevenção do estresse como fator de principal de proteção ao adoecimento psíquico. ${ }^{18}$

Os espaços de escuta e diálogo, além de serem identificados como estratégias de enfrentamento do estresse, têm característica voltada para a promoção de momentos de diálogo e partilha das dificuldades vivenciadas ${ }^{19}$, como também promove a criação de mecanismos de apoio aos profissionais, de reflexão e discussão de novos arranjos que permitam uma melhor dinamização do serviço e efetivação do cuidado.

\section{CONSIDERAÇÕES FINAIS}

Os profissionais de enfermagem participantes da pesquisa, embora sejam responsáveis pelo cuidado às pessoas em sofrimento psíquico, estão sujeitos a vivenciar situações estressantes, pela demanda emocional influenciada pela insegurança ou pelas dificuldades que perpassam o processo de trabalho em saúde mental.

Todavia, apesar de reconhecer o estresse decorrente das suas práticas profissionais, os sujeitos desta pesquisa relataram algumas estratégias de coping que podem amenizar as situações estressantes, como o apoio social, a música e os espaços de escuta, a fim de atender as demandas dos profissionais que trabalham em saúde mental e permitir a possibilidade concreta de diálogo e reflexão sobre a importância de também cuidar daqueles que cuidam.

Constituíram-se limitações deste estudo a amostra ter sido coletada apenas em um serviço de saúde mental, e apenas em uma categoria de trabalhadores, no entanto, possibilitou observar as consequências trazidas pelo ambiente laboral, bem como a necessidade de uma discussão ampla sobre a saúde do trabalhador e a criação de recursos para oferecer suporte a estes profissionais.

Sugere-se que os resultados aqui abordados favoreçam a reflexão dos profissionais e gestores da saúde, quanto à necessidade de discutir, elaborar e principalmente operacionalizar políticas de cuidado voltadas aos cuidadores. 


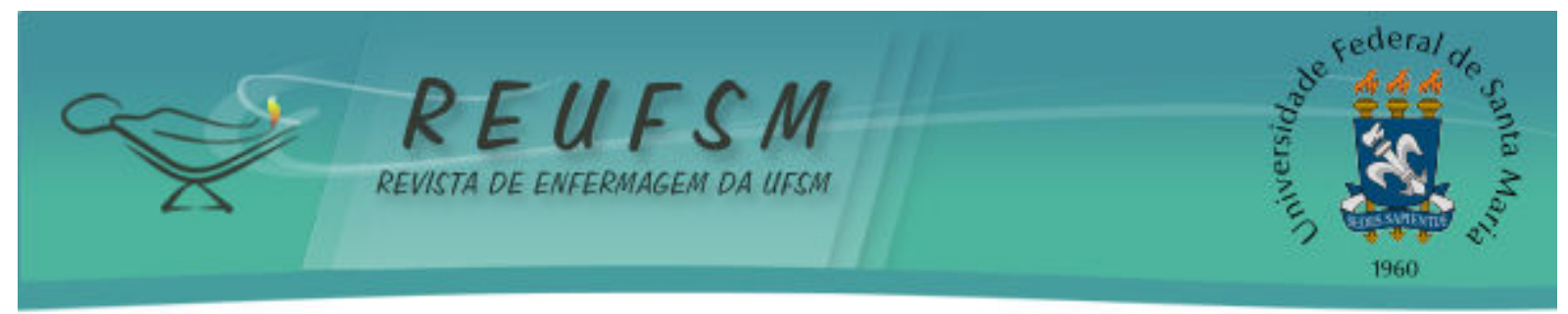

\section{REFERÊNCIAS}

1. Brasil. Ministério da Saúde. Relatório final da III Conferência Nacional de Saúde Mental. Brasília (DF): Ministério da Saúde, Conselho Nacional de Saúde; 2002.

2. Brasil. Ministério da Saúde. Saúde Mental no SUS: os centros de atenção psicossocial. Brasília (DF): Ministério da Saúde; 2004. (Série F. Comunicação e Educação em Saúde).

3. Gomes DJ, Araújo TM, Santos KOB. Condições de trabalho e de saúde de trabalhadores em saúde mental em Feira de Santana, Bahia. Rev Baiana de Saúde Publica [Internet] . 2011 [acesso em 2014 out 27]; 35 Supl 1:211-30. Disponivel em: http://inseer.ibict.br/rbsp/index.php/rbsp/article/viewFile/157/152.

4. Smeltzer SC,Bare BG. Brunner\&Suddarth: tratado de enfermagem médico-cirúrgica. $10^{\mathrm{a}}$ ed. Rio de Janeiro (RJ): Guanabara-Koogan; 2006.

5. Flick U. Introdução à pesquisa qualitativa. $3^{\text {a }}$ ed. Porto Alegre (RS): Artmed; 2009.

6. Bardin L. Análise de conteúdo. 2ª ed. Lisboa: Edições 70; 2009.

7. Brasil. Ministério da Saúde. Conselho Nacional de Saúde. Comissão Nacional de Ética em Pesquisa. Resolução CNS n 196, de 16 de outubro de 1996. Aprova as diretrizes e normas regulamentadoras de pesquisas envolvendo seres humanos. Brasília (DF): Conselho Nacional de Saúde; 1996.

8. Alvim MB. A relação do homem com o trabalho na contemporaneidade: uma visão crítica fundamentada na gestalt-terapia. Estud Pesqui Psicol [Internet]. 2006 [acesso em 2013 jun 10];6(2):122-30. Disponível em: www.revispsi.uerj.br/v6n2/artigos/pdf/v6n2a10.pdf.

9. Mello Filho J, Burd M. Psicossomática hoje. $2^{\mathrm{a}}$ ed. Porto Alegre (RS): Artmed; 2010.

10. PaschoaL T, Tamayo A. Impacto dos valores laborais e da interferência família-trabalho no estresse ocupacional. Psic Teor Pesq [Internet]. 2005 [acesso em 2014 out 27];21(2):173-80. Disponível em: http://www.scielo.br/pdf/ptp/v21n2/a07v21n2.pdf.

11. Amarante $P$, coordenador. Loucos pela vida: a trajetória da reforma psiquiátrica no Brasil. $2^{\mathrm{a}}$ ed, $5^{\mathrm{a}}$ reimpres. Rio de Janeiro (RJ): Fiocruz; 2010.

12. Gauer GJC, Franco RS, Zogbi H, Marini PA, Diefenthaeler EC, Cataldo Neto A. Estratégias dos profissionais de saúde para cuidar dos que cuidam. Bioética [Internet]. 2006 [acesso em 2013 jul 10];14(2):171-80. Disponível em: http://revistabioetica.cfm.org.br/index.php/revista_bioetica/article/viewFile/20/23.

13. Aragão EIS, Viera SS, ALVES MGG, Santos AF. Suporte social e estresse: uma revisão de literatura. Psicologia em foco [Internet]. 2009 [acesso em 2014 out 28];2(1):79-90. Disponível em: http://linux.alfamaweb.com.br/sgw/downloads/161_115245_ARTIGO8Suportesocialeestresse-umarevisaodaliteratura.pdf.

14. Taets GGC, Barcellos LRM. Música no cotidiano de cuidar: um recurso terapêutico para enfermagem. Rev Pesqui Cuid Fundam Online [Internet]. 2010 [acesso em 2013 jan 15];2(3):1009-16. Disponível

http: / / dialnet.unirioja.es/servlet/articulo?codigo=3651916.

15. Ribeiro RP, Martins JT, Marziale MHP, Robazzi MLCC. O adoecer pelo trabalho na enfermagem: uma revisão integrativa. Rev Es Enferm USP [Internet]. 2012 [acesso em 2014 29 out];46(2):495-504. Disponível em: http://www.scielo.br/scielo.php?script=sci_arttext\&pid=S0080-62342012000200031. 


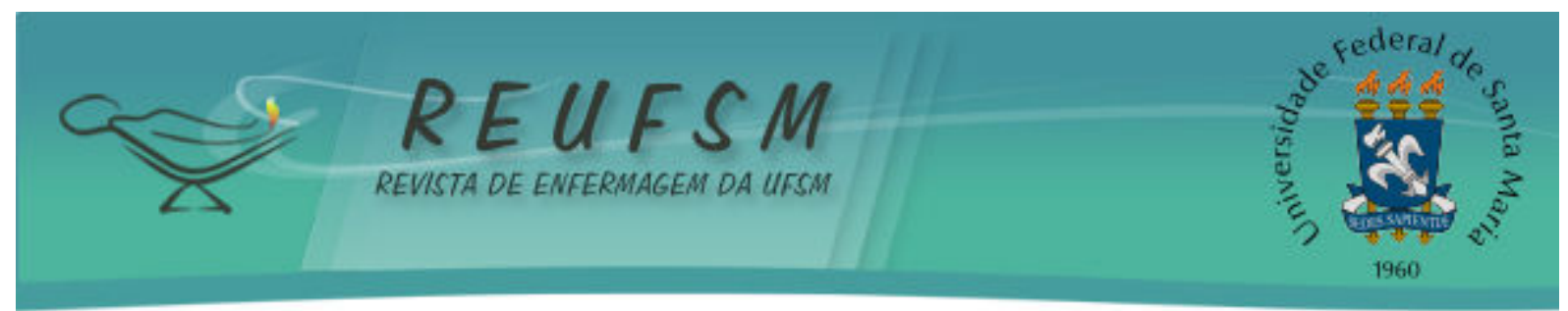

16. Costa JRA, Lima JV. Estratégias para o enfermeiro enfrentar o stresse em seu trabalho com portador de transtorno mental. Rev Gaúch Enferm [Internet]. 2003 [acesso em 2013 nov 12];24(3):325-35. Disponível em: http://www.seer.ufrgs.br/index.php/RevistaGauchadeEnfermagem/article/viewFile/4480 /2419.pdf.

17. Amestoy SC, Schwartz E,Thoferhrn MB. A humanização do trabalho para os profissionais de enfermagem. Acta Paul Enferm [Internet]. 2006 [acesso em 2013 jul 9];19(4):444-9. Disponível em: http://www.scielo.br/scielo.php?script=sci_arttext\&pid=S010321002006000400013

18. Martins CC, Valente GSC. Influence of the stress in the occupational nurse's health who works in hospital emergency. Rev Enferm UFPE Online [Internet]. 2010 [acesso em 2013 out 20];4(2):533-8. Disponível em: http://www.revista.ufpe.br/revistaenfermagem/index.php/revista/article/view/697/pdf_ 31

19. Barboza MCN, Braga LL, Perleberg LT, Bernardes LS, Rocha IC. Estresse ocupacional em enfermeiros atuantes em setores fechados de um hospital de Pelotas/RS. Rev Enferm UFSM [Internet]. 2013 [acesso em 2014 out 29]; 3(3):374-82. Disponível em: http://cascavel.ufsm.br/revistas/ojs2.2.2/index.php/reufsm/article/view/7624/pdf.

Data de recebimento: $29 / 05 / 2014$

Data de aceite: $11 / 12 / 2014$

Contato com autor responsável: Lorena de Farias Pimentel Costa

Endereço postal: Av. Dom Pedro II. No 899, $1^{\circ}$ andar. Prata. Campina Grande - PB. CEP. 58400-565.

E-mail: lorenafarias@outlook.com 